Research Article

\title{
Leaf Assisted Green Synthesis of Silver Nanoparticles from Syzygium Alternifolium (Wt.) Walp. Characteri- zation and Antimicrobial Studies
}

\author{
Pulicherla Yugandhar , Nataru Savithramma \\ Dept. of Botany, Sri Venkateswara University, Tirupati-517502, Andhra Pradesh, India \\ Corresponding author: E-mail: yugandharbotany@gmail.com
}

Received: Feb. 10, 2015; Accepted: Apr. 24, 2015; Published: Apr. 30, 2015.

Citation: Pulicherla Yugandhar and Nataru Savithramma. Leaf Assisted Green Synthesis of Silver Nanoparticles from Syzygium Alternifolium (Wt.) Walp. Characterization and Antimicrobial Studies. Nano Biomed. Eng. 2015, 7(2), 29-37.

DOI: 10.5I0I/nbe.v7i2.p29-37.

\begin{abstract}
Development of environmentally benign methods for synthesis of nanoparticles is an evolving important branch of nanotechnology. In the present study we report a green method for synthesis of stable silver nanoparticles (SNPs) from aqueous leaf extract of Syzygium alternifolium an endemic medicinal plant to Southern Eastern Ghats. These green synthesized nanoparticles are characterized by using UV-VIS spectroscopy, FTIR, XRD, AFM, SEM with EDAX and TEM. The colour change from yellow to grey is observed upon synthesis and $448 \mathrm{~nm}$ peak was obtained from UV-VIS spectroscopic analysis. FTIR spectroscopic studies confirms that phenols and proteins of leaf extract is main responsible for capping and stabilization of these SNPs. Crystallographic studies from XRD indicated the SNPs are crystalline in nature and owing $44 \mathrm{~nm}$ size. High resolution and magnification studies with AFM, SEM and TEM analysis revealed that the nanoparticles are spherical in shape having the size range from 7 to $44 \mathrm{~nm}$. EDAX pattern of synthesized SNPs showed 47.28 weight percentage of Ag metal in the sample indicate the purity of sample. Further, the antimicrobial studies of these green synthesized SNPs show high toxicity towards different bacterial and fungal isolates. The results revealed that the selected medicinal plant possess the potentiality towards the synthesis of narrow range nanoparticles also combat with the pathogens.
\end{abstract}

Keywords: Syzygium alternifolium; Green synthesis of silver nanoparticles; Characterization; antimicrobial activity

\section{Introduction}

Synthesis of metallic nanoparticles with small size and shape with desired properties is one of the fascinating research areas in nanotechnology. Conventional methods for synthesizing metallic nanoparticles are quite often toxic and non-degradable. Green synthesis of nanoparticles with plants has received increased attention due to the development of eco-friendly and cost effective methods. Recently green synthesis of nanoparticles from plant materials as reducing agents like Indium oxide nanoparticles from Aloe vera [1] Iron oxide nanoparticles from Medicago sativa [2] Palladium nanoparticles from Cinnamomum camphora [3] Copper nanoparticles from Magnolia kobus [4] Cadmium Oxide nanoparticles 
from Achillea wilhelmsii [5] Calcium nanoparticles from Boswellia ovalifoliolata [6] Gold nanoparticles from Avena sativa [7] Zinc oxide nanoparticles from Catharanthus roseus [8] and Silver nanoparticles from Adansonia digitata [9]. Silver has long been known to have strong inhibitory and bactericidal effects as well as a broad spectrum of antimicrobial activities, even at low concentrations [10]. Hence, among the metal nanoparticles, SNPs synthesized from medicinal plants have received much attention in various biological activities like antibacterial [11] antifungal [12] anthelmintic [13] anti-larvicidic [14] antioxidant [15] anti-cancer [16] anti-inflammatory [17] Hepatoprotective [18] and Wound healing [19] activities.

The importance of silver has been recognized in chemistry, physics and biology due to its unique properties. Conventional methods to synthesize silver nanoparticles are mainly by different chemical, physical and microbial approaches. The most common approaches for synthesis of SNPs in chemical approach is to use Sodium borohydride $\left(\mathrm{NaBH}_{4}\right)$ [20] and Citrate [21] as reducing agents. Topical exposure of $\mathrm{NaBH}_{4}$ severely irritate skin and eye, breathing $\mathrm{NaBH}_{4}$ irritate nose and throat, higher exposure can cause pulmonary edema, very higher exposure may affect nervous system. Citrate causes hypocalcaemia, fatigue, paresthesia and muscle spasms. Common methods for synthesis of SNPs by Physical approaches are laser ablation [22] and evaporation/condensation method which could be carried out using a tube furnace [23]. Physical synthesis of silver nanoparticles using tube furnace at atmospheric pressure has some disadvantages, it occupies large space, consumes a great amount of power energy [24] and laser ablation method is not a cost effective method. These chemical and physical methods are complicated, expensive and cause potential environmental and biological hazards. In recent times, 50-120 nm sized silver nanoparticles are synthesized from Bacillus Sps. acts as good reducing agent [25] but, significant drawback of microbe mediated synthesis is not feasible industrially due its lab maintenance. Therefore biosynthesis of SNPs by using plant materials is easy, efficient, and eco friendliness in comparison to chemical mediated or microbe mediated synthesis [26].

Syzygium alternifolium belongs to the family Myrtaceae grown in high altitude regions of Tirumala, Chittoor and Kadapa districts of South Eastern Ghats of Andhra Pradesh, India. Reddy \& Reddy [27] stated that $S$. alternifolium is an endemic and globally endangered species to these areas. S. alternifolium locally known as mogi or adavi nerudu, the fruits of this plant are made into fine powder and taken orally for the treatment of diarrhoea [28] and diabetes [29]. Stem bark extract is used to treat external wounds [30] and to regulate blood sugar levels [31].Some of the researchers scientifically proven that the leaves having antimicrobial activity [32] hypoglycemic and antihyperglycemic activity [33] antioxidant [34] and anticancer activity [35].

\section{Experimental section}

\section{Synthesis of SNPs}

S. alternifolium leaves are collected from Naagatheertham area of Tirumala hills of Eastern Ghats range and identified by herbarium deposited (Voucher No.121) in the Department of Botany, Sri Venkateswara University, Tirupati. $25 \mathrm{gms}$ of powdered leaf was extracted with $100 \mathrm{ml}$ of milli $q$ water on boiling water bath for 1 hour. Filter the content with whatman No. 1 filter paper and stored at room temperature for green synthesis of SNPs. $5 \mathrm{ml}$ of plant extract was taken in $250 \mathrm{ml}$ conical flask, titrated with $50 \mathrm{ml}$ of $1 \mathrm{mM} \mathrm{Ag}\left(\mathrm{NO}_{3}\right)_{2}$ at $60-80^{\circ} \mathrm{C}$ with the help of magnetic stirrer. The contents were centrifuged at $10000 \mathrm{rpm}$ for 20 minutes to avoid the presence of any biological impurities. Further, it is used for characterization and antimicrobial studies.

\section{Characterization of SNPs}

UV-VIS absorption spectra of SNPs were measured by using a Spectro UV 2080 Double beam 1200 L/ $\mathrm{mm}$ spectrophotometer, Analytical technologies, India. Fourier Transform Infra-Red (FT-IR) spectra of synthesized SNPs was analysed in the range of 4000 to $500 \mathrm{~cm}^{-1}$ with an ALPHA interferometer (ECOATR), Bruker, Ettlingen, Karlsruhe, Germany by $\mathrm{KBr}$ pellet method. Crystalline metallic silver nanoparticles were examined by using an X-Ray Diffractometer (XRD) (Shimadzu, XRD-6000) equipped with $\mathrm{Cu} \mathrm{K \alpha}$ radiation source using $\mathrm{Ni}$ as filter at a setting of 30 $\mathrm{kV} / 30 \mathrm{~mA}$. Atomic Force Microscopy (AFM) analysis was done by NOVA NT-MDT SOLVER NEXT, Russia. Scanning Electron Microscopy (SEM) and Percentage presence of silver ions in the synthesized SNPs was done by using a FEI Quanta 200 FEG HRSEM machine equipped with EDAX instrument. 
Transmission Electron Microscopy (TEM) analysis is performed by using HF-3300 advanced 300 kV TEM/ STEM from Hitachi.

\section{Antimicrobial studies of SNPs}

The antimicrobial activity of green synthesized silver nanoparticles from leaf extract was analyzed against two Gram positive bacterial strains like Bacillus subtilis, Staphylococcus aureus and five Gram negative bacterial strains like Escherichia coli, Klebsiella pneumoniae, Proteus vulgaris, Pseudomonas aeruginosa and Salmonella typhimurium. Antifungal studies were carried out in five fungal strains like Alternaria solani, Aspergillus niger, Aspergillus flavus, Penicillium chrysogenum and Trichoderma harzianum procured from Dept. of Microbiology, Sri Venkateswara University, Tirupati. Disc diffusion method [36] was followed for testing antimicrobial activity against green synthesized SNPs and comparative studies were made with plant leaf extract as a positive control, 1 $\mathrm{mM} \mathrm{Ag}\left(\mathrm{NO}_{3}\right)_{2}$ as negative control and Streptomycin/ Fluconazole as a standard. $7 \mathrm{~mm}$ sterile discs were prepared from whatman No.1 filter paper and $20 \mu \mathrm{l}$ of each extract was loaded on separate discs with the help of micro pipette and allowed to air dry for one hour in aseptic conditions. Freshly prepared nutrient agar media for bacteria and potato dextrose agar media for fungi as a nutrient substrate was poured into sterile petriplates and allowed for 30 minutes for solidification. The plates were swabbed with microbial cultures and placed the previously prepared discs, the experiment was carried out in triplicates. The plates were incubated at $37{ }^{\circ} \mathrm{C}$ for 24 to $48 \mathrm{~h}$ then the zone of inhibition was measured with the help of scale and tabulated the results.

\section{Results and Discussion}

The formation of silver nanoparticles was monitored by UV-VIS absorption spectra. The colour change from pale yellow to grey is observed and a typical absorption peak obtained at $448 \mathrm{~nm}$, it is due to surface plasmon resonance of silver nanoparticles in the reaction mixture (Fig. 1). Same type of results was observed in Albizia adianthifolia leaf mediated synthesis of silver nanoparticles [37]. FTIR spectrum of synthesized SNPs was carried out to know the possible biomolecules responsible for capping and stabilization of nanoparticles. For this the FTIR spectrum was analysed between the scan rangesfrom 4000 to $500 \mathrm{~cm}^{-1}$. Here

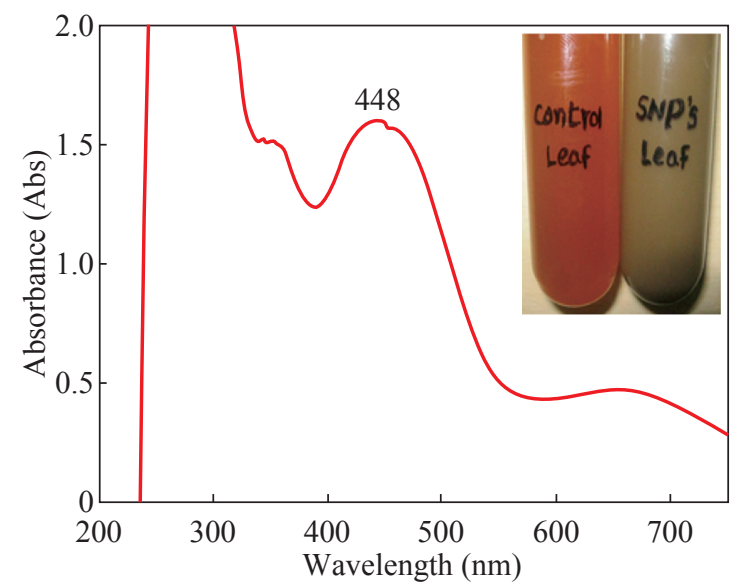

Fig. 1 UV-VIS analysis of synthesized SNPs shows peak at 448 $\mathrm{nm}$. In inset the colour change i.e., yellow to grey is observed.

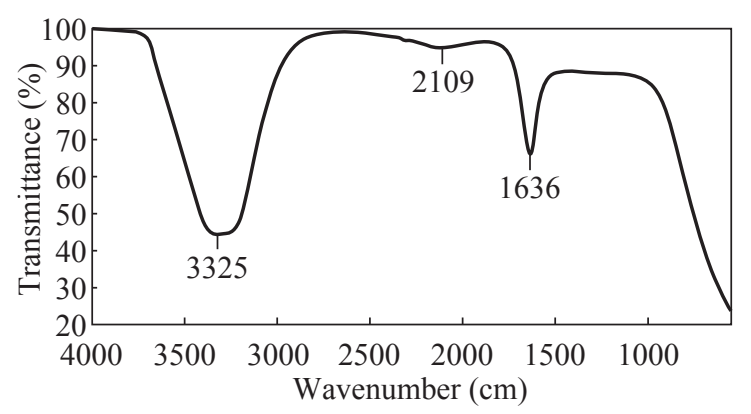

Fig. 2 FTIR spectra of green synthesized SNPs from leaf extract of $S$. alternifolium.

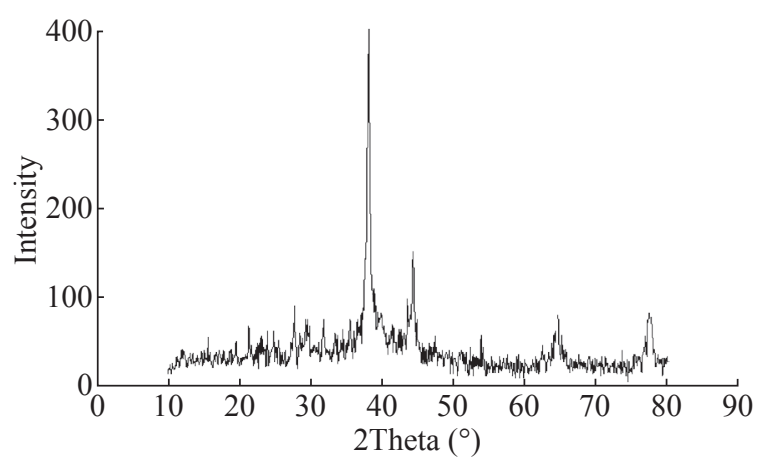

Fig. 3 XRD pattern of green synthesized SNPs from leaf extract of $S$. alternifolium.

the broad peaks obtained at $3325 \mathrm{~cm}^{-1}$ assigned for $\mathrm{O}-\mathrm{H}$ bond of phenols and $1636 \mathrm{~cm}^{-1}$ assigned for $\mathrm{N}-\mathrm{H}$ bond of primary amines (Fig. 2). These FTIR studies suggested that the hydroxyl groups of phenols and amide groups of proteins forming a layer to the nanoparticles and acting as capping agents to prevent agglomeration and providing stability to the medium. Same type of results was found in Myristica fragrans seed extract mediated synthesis of silver nanoparticles [38]. The nature of the nanoparticles synthesized from leaf extract was analysed by X-ray diffraction analysis. The XRD pattern of plant derived SNPs shows four 
intensive peaks at $38,44,64$ and 77 of $2 \theta$ degrees of $\mathrm{X}$-axis corresponds to $111,200,220$ and 311 bragg reflections of Y-axis (Fig. 3). These bragg reflections confirms that the nanoparticles are crystalline in nature. The mean particle diameter of synthesized SNPs is 44 $\mathrm{nm}$, calculated according to Debye-Scherrer equation $(\mathrm{D}=\mathrm{k} \lambda / \beta \cos \theta)$. The Full Width at Half Maximum (FWHM) values i.e., $k=0.44$ were derived from 38,44 , 64 and 77 bragg reflections of $\mathrm{X}$-axis.

AFM was used as a primary method to monitor size, morphology and agglomeration pattern of surface topology of nanoparticles. The $1 \mu \mathrm{m}$ resolution studies of AFM reveals the particles are spherical in shape, having the size range from 22 to $44 \mathrm{~nm}$. A statistical treatment of AFM images was performed using specially designed image processing software (NOVATX) to further exploit these images to explore the 3D nanostructures. The average size of the nanoparticles from particular magnified area is analysed by these software i.e., $41 \mathrm{~nm}$. Here the $\mathrm{X}$-axis shows size of the particles and $\mathrm{Y}$-axis showing number of particles (Fig. 4). SEM with EDAX analysis provides further insight into the morphology and size of the nanoparticles along with presence of different metal concentrations in the sample. $500 \mathrm{~nm}$ resolution studies of green synthesized SNPs shows spherical shape with 21-31 nm size of nanoparticles and EDAX spectrum of these synthesized SNPs shows 47.28 weight percentage of Ag metal in the sample along with $15.51 \%$ of Carbon, $02.08 \%$ of Nitrogen, $03.14 \%$ of Oxygen, $01.27 \%$ of Sodium,
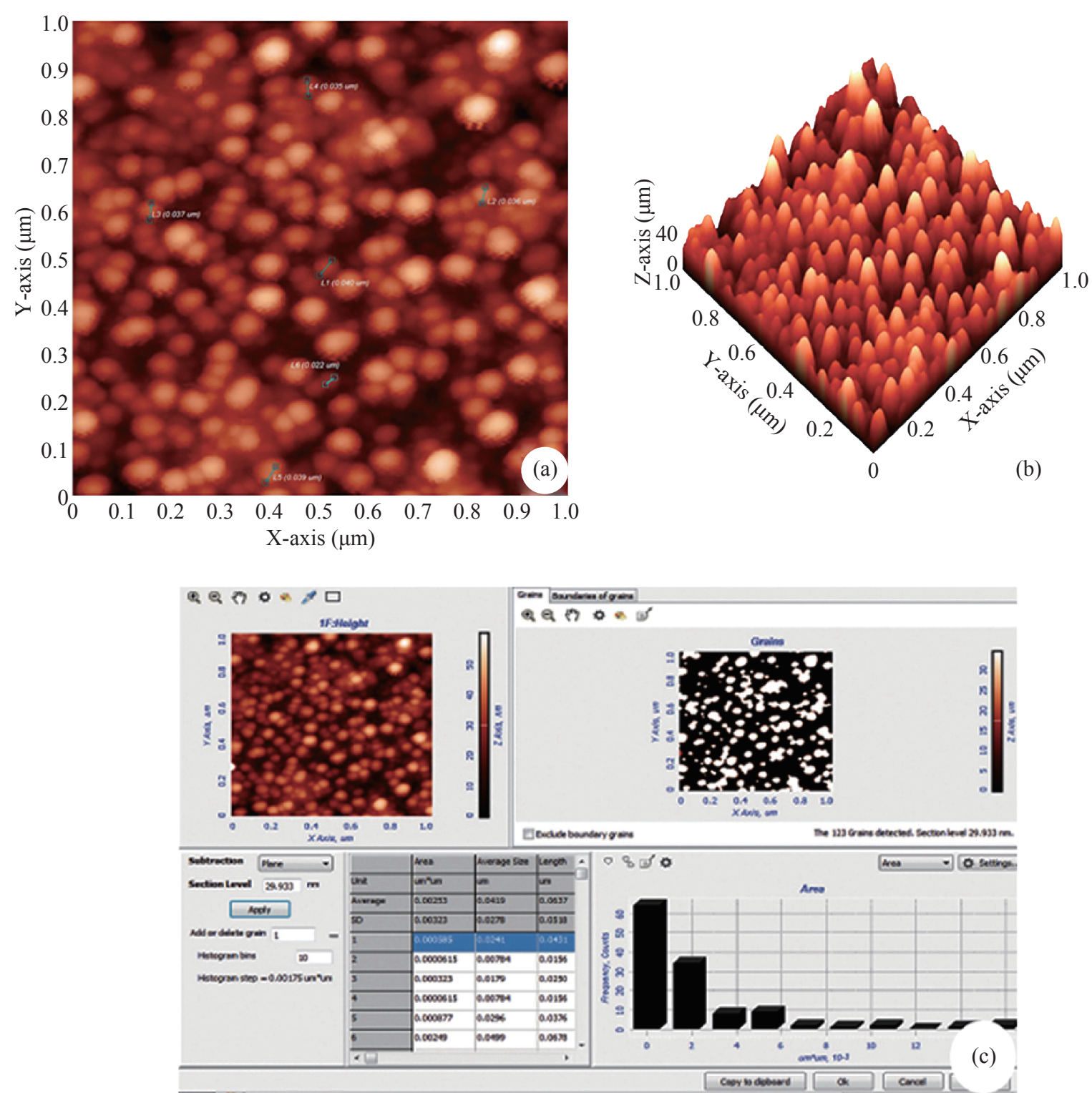

Fig. 4 (a) $1 \mu \mathrm{m}$ resolution studies with AFM shows, the particles are spherical in shape with 22 to $44 \mathrm{~nm}$ size (b) 3D structure of SNPs (c). Average size of the nanoparticles i.e., $41 \mathrm{~nm}$ were analysed by NOVA-TX software. 


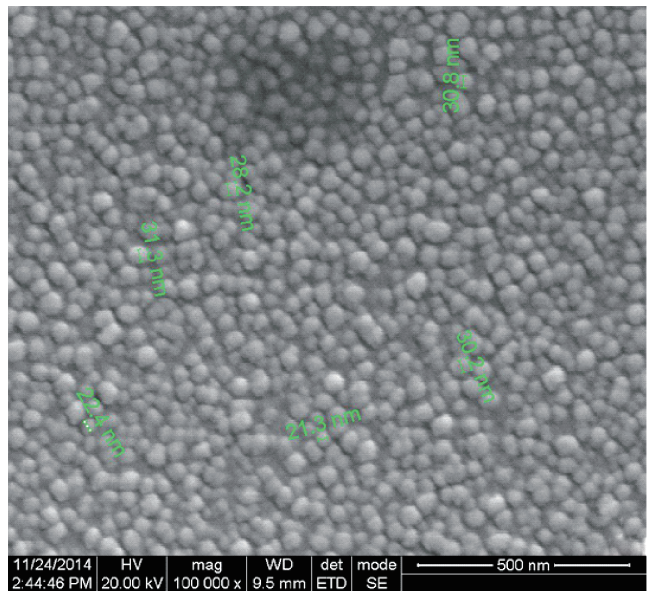

(a)

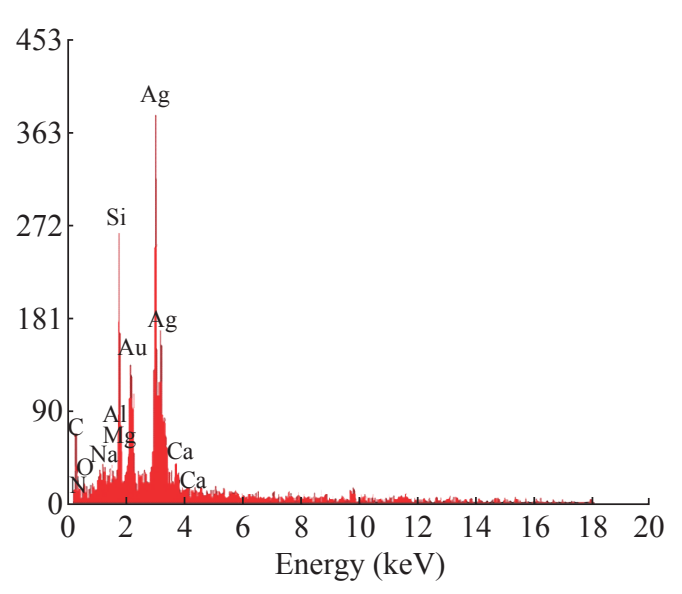

(b)

Fig. 5 (a) $500 \mathrm{~nm}$ resolution studies of green synthesized SNPs shows spherical shape with 21-31 nm size. (b) EDAX analysis of green synthesized SNPs shows 47.28 weight percentage.

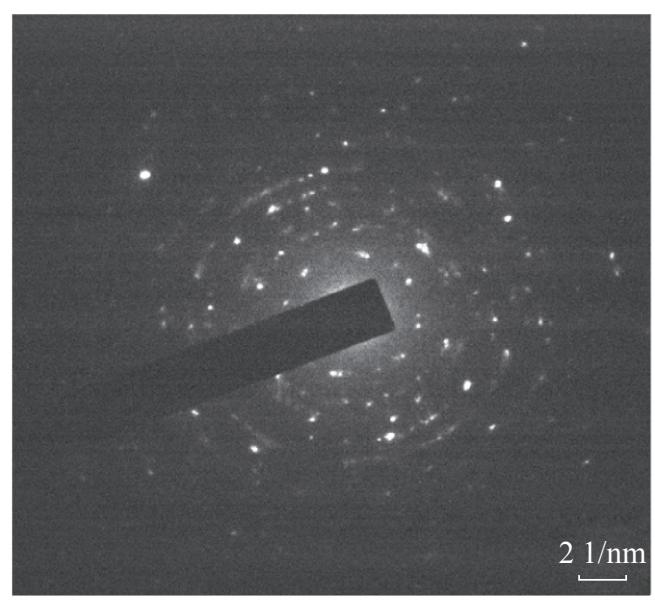

(a)

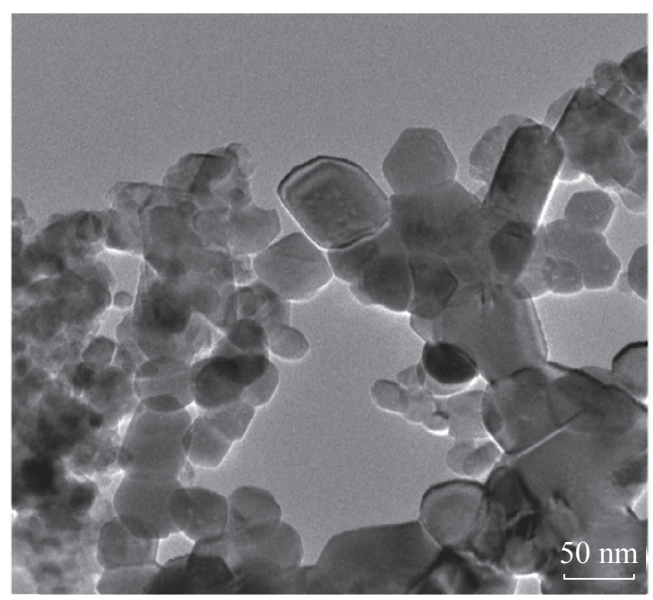

(b)

Fig. 6 (a) Selected area electron diffraction (SAED) of green synthesized SNPs, (b) $50 \mathrm{~nm}$ resolution studies of green synthesized SNPs shows mostly spherical shaped nanoparticles with 5-7 nm size.

$01.13 \%$ of Magnesium, $00.43 \%$ of Aluminium, $09.79 \%$ of Silicon, $17.06 \%$ of Aurum and $02.31 \%$ of Calcium. 47.28 weight percentage of Ag metal in the sample indicates the high purity of sample (Fig. 5). Presence of $\mathrm{C}, \mathrm{N}$ and $\mathrm{O}$ in the sample analyzed by EDAX indicates proteins as a capping material towards these silver nanoparticles [39]. Higher resolution studies with TEM analysis, to know the size, morphology and agglomeration pattern of nanoparticles. Selected area electron diffraction (SAED) pattern of TEM shows the nanoparticles are crystalline in nature. $50 \mathrm{~nm}$ resolution studies of nanoparticles on TEM analysis reveals the nanoparticles are 7-10 $\mathrm{nm}$ in size owing spherical shape without any agglomeration observed between the particles (Fig. 6). From these microscopic studies with AFM, SEM and TEM analyses reveals these green synthesized silver nanoparticles from $S$. alternifolium shows the size range from 7 to $44 \mathrm{~nm}$ having spherical shape without any agglomeration between the particles. In our previous studies, synthesis of silver nanopatricles from fruit extract of S. alternifolium shows spherical shaped nanoparticles with the size up to $68 \mathrm{~nm}$ [40]. In this study, the nanoparticles are spherical in shape having size range up to $44 \mathrm{~nm}$. Lesser size of nanoparticles formed in this leaf assisted synthesis is may be due to high quantity of phytoconstituents in the leaf instead of fruit.

These green synthesized silver nanoparticles were assessed for antimicrobial activities against two gram positive and five gram negative bacteria's as well as five fungal strains. Among the bacteria the highest inhibition zones were observed in S. typhimurium followed by $P$. vulgaris, $P$. aeruginosa, K. pneumonia, E. coli, B. subtilis and $S$. aureus. Whereas in the case 

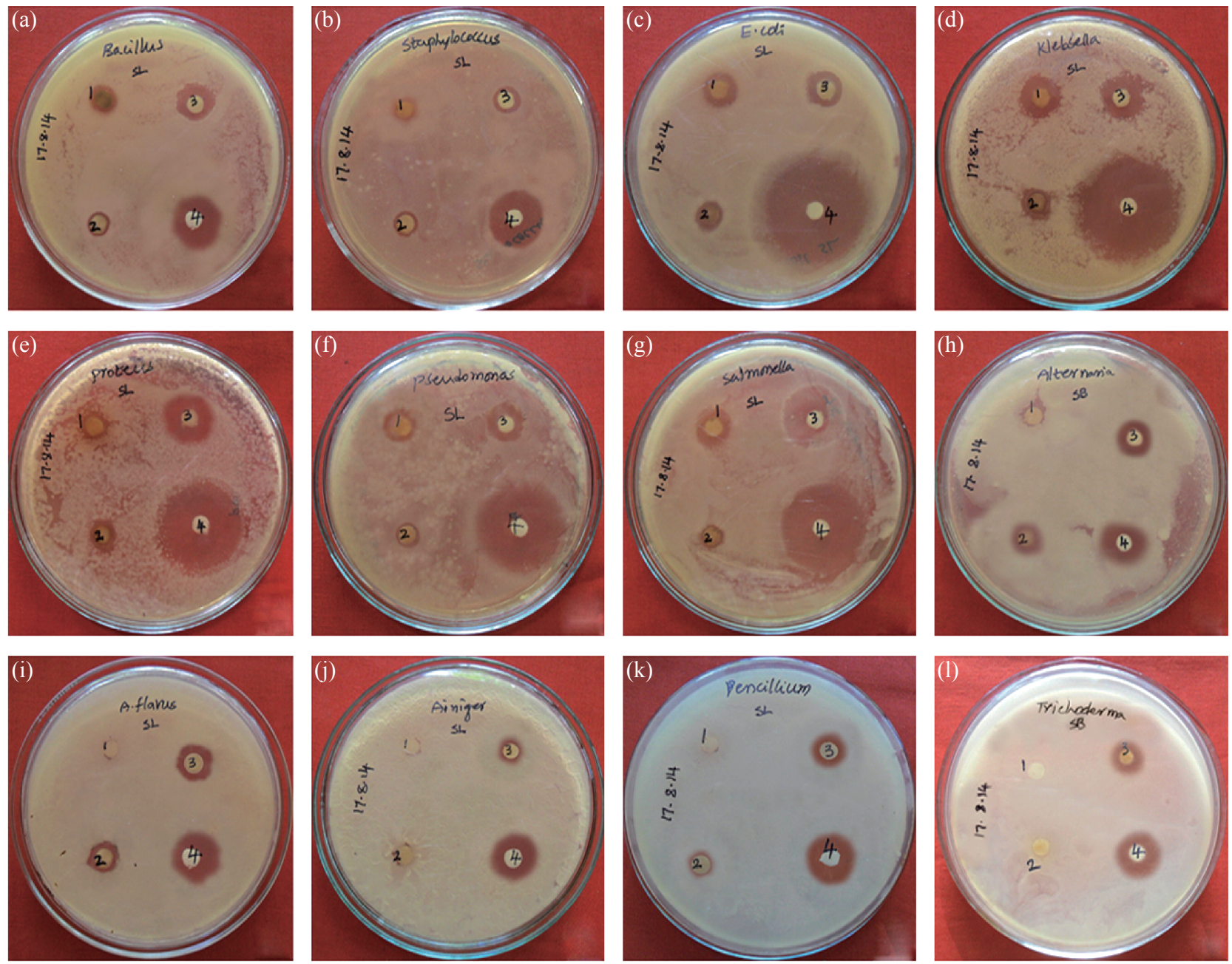

Fig. 7 Antimicrobial activity of green synthesized SNPs from leaf extract of S. alternifolium (a) B. subtilis, (b) S. aureus, (c) E. coli, (d) K. pneumonia, (e) P. vulgaris, (f) P. aeruginosa, (g) S. typhimurium, (h) A. solani, (i) A. flavus, (j) A. niger, (k) P. chrysogenum, (1) T. harzianum, (1) Plant extract (2) $\mathrm{Ag}\left(\mathrm{NO}_{3}\right)_{2}$ (3) SNPs, (4) Streptomycin/Fluconazole.

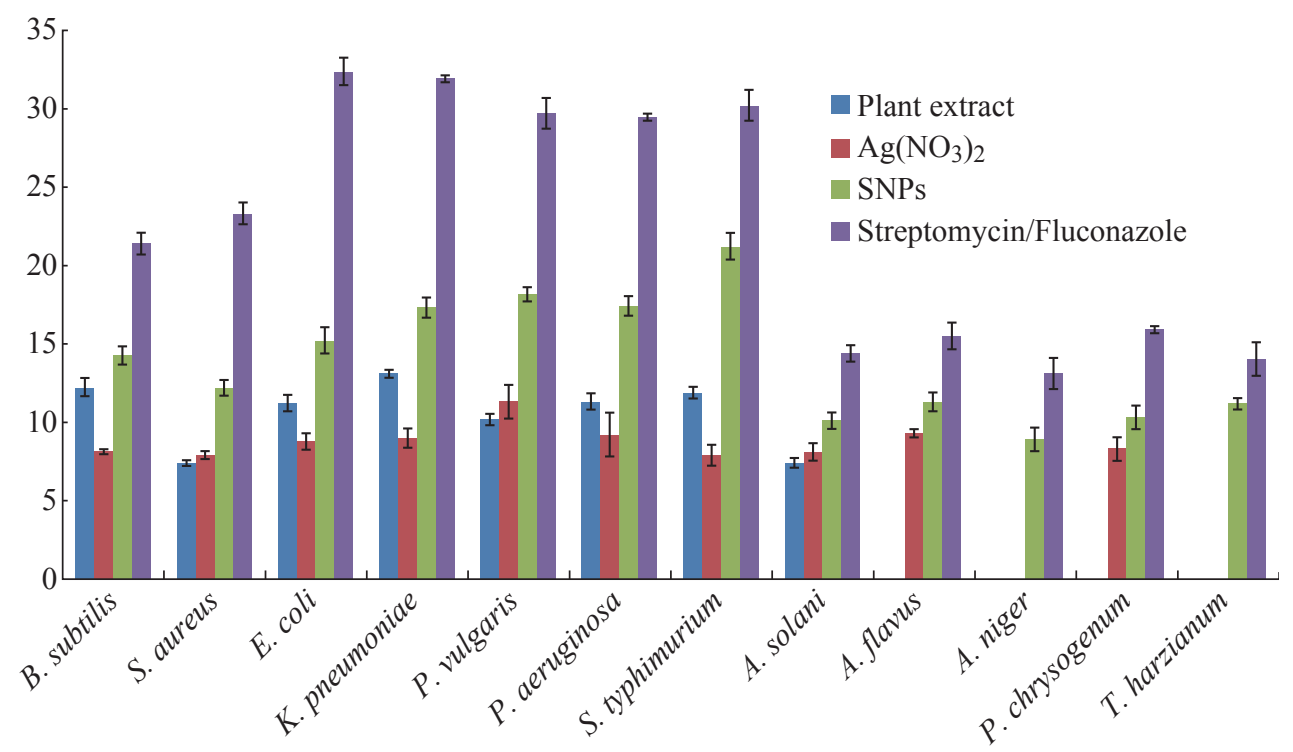

Fig. 8 Comparison of zone of inhibition of green synthesized SNPs with different extracts on clinically isolated bacteria and fungi.

of fungi, the highest zone of inhibition were observed in A. flavus followed by T. harzianum, P. chrysogenum,
A. niger and A. solani (Fig. 7, Fig. 8, Table 1). The SNPs shows less significant effect on Gram positive 
Table 1 EDAX analysis of green synthesized SNPs

\begin{tabular}{ccc}
\hline S. No & Element & Weight $(\%)$ \\
\hline 1 & $\mathrm{C}$ & 15.51 \\
2 & $\mathrm{~N}$ & 02.08 \\
3 & $\mathrm{O}$ & 03.14 \\
4 & $\mathrm{Na}$ & 01.27 \\
5 & $\mathrm{Mg}$ & 01.13 \\
6 & $\mathrm{Al}$ & 00.43 \\
7 & $\mathrm{Si}$ & 09.79 \\
8 & $\mathrm{Au}$ & 17.06 \\
9 & $\mathrm{Ag}$ & 47.28 \\
10 & $\mathrm{Ca}$ & 02.31 \\
\hline
\end{tabular}

bacteria than on Gram negative bacteria. This is due to the Gram positive bacteria having thick layers of peptidoglycons (together with polypeptide contains proteins) when compare to the Gram negative bacteria. Due to this, penetration of SNPs through cell membrane is easy in case of Gram negative bacteria and inhibition of growth is more possible. The cell walls of fungi is made up of chitin (a type of polysaccharide contains nitrogen) is having more complex structure than bacteria. From these observations, the results obtained here is bacterial strains shows high susceptibility to SNPs when compare to fungi. 20-25 nm sized, spherical shaped silver nanoparticles synthesized from olive leaf extract shows good antibacterial activity against $S$. aureus, P. aeruginosa and E. coli [41]. Euphorbia hirta leaf mediated synthesis of silver nanoparticles having spherical shape with 40-45 nm size shows good antifungal efficacy [42]. SNPs may attach to the surface of the cell membrane and disturb its permeability and cause structural changes on cell membrane of bacteria [43] and destructing membrane integrity of fungal spores [44] leads to cell death. Some of the scientists state that the SNPs penetrate inside the bacteria and fungi causing damage by interacting with electron phosphorous and sulphur containing compounds such as DNA and proteins, resulting in cell death [45].

\section{Conclusions}

In the present study we develop a fast, eco-friendly and cost effective method for silver nanoparticles in a greener way. This green method avoids deficiencies of chemical, physical and bacteria mediated approaches instead of plant extracts as reducing agents. Another advantage in this green synthesis approach is nanoparticles are stable for a long time. Further these nanoparticles showed good antimicrobial activity against clinically isolated pathogenic microorganisms. Hence, this type of greener methods for production of silver nanoparticles at lower cost with natural sources is an utmost important to industrial scale due to high importance in various medical fields. High quantity production of nanoparticles with little volume of plant extract is high measurable significance in this medicinal endemic plant.

\section{Acknowledgement}

The authors are highly thankful UGC-BSR for providing meritorious research fellowship and highly grateful to DST-PURSE, Sri Venkateswara UniversityTirupati, JNTU-Hyderabad, SAIF-IIT Madras for providing technical support.

\section{References}

[1] S. Maensiria, P. Laokula, J. Klinkaewnaronga, et al., Indium oxide $\left(\operatorname{In}_{2} \mathrm{O}_{3}\right)$ nanoparticles using Aloe vera plant extract: Synthesis and optical properties. J. Optoelectron. Adv. Mater., 2008, 10: 161-165.

[2] R. Herrera-Becerra, C. Zorrilla, J.L. Rius, J.A. Ascencio. Electron microscopy characterization of biosynthesized iron oxide nanoparticles. Appl. Phys. A: Mater. Sci. Process, 2008, 9: 241-246.

[3] X. Yang, L. Qingbiao, H. Wang, et al., Green synthesis of palladium nanoparticles using broth of Cinnamomum camphora leaf. J. Nanopart. Res., 2009, 12: 1589-1598.

[4] H.J. Lee, J.Y. Song, B.S. Kim. Biological synthesis of copper nanoparticles using Magnolia kobus leaf extract and their antibacterial activity. J. Chem. Technol. Biotechnol, 2013, 88: 1971-1977.

[5] K.A. Javad, M. Sasan. Phytosynthesis of Cadmium Oxide Nanoparticles from Achillea wilhelmsii Flowers. $J$. Chem., 2013, 2013: 1-4.

[6] P. Yugandhar, N. Savithramma. Green synthesis of calcium carbonate nanoparticles and their effects on seed germination and seedling growth of Vigna mungo (L.). Hepper. Int. J. Adv. Res., 2013, 1: 89-103.

[7] A. Veronica, H. Isaac, R.P.V. Jose, et al., Size controlled gold nanoparticle formation by Avenasativa biomass: use of plants in nanobiotechnology. J. Nanopart. Res., 2004, 6: 377-382.

[8] G. Bhumi, N. Savithramma. Biological Synthesis of Zinc oxide Nanoparticles from Catharanthus roseus (L.) G. Don. Leaf extract and validation for antibacterial activity. Int. J. Drug. Dev. Res., 2014, 6: 208-214.

[9] Ch. Marutikesava Kumar, P. Yugandhar, D. Suhrulatha, N. Savithramma. Synthesis, Characterization and Antimicrobial studies of stem bark mediated synthesis of silver nanoparticles from Adansonia digitata (L.). $J$. Pharm. Sci. Res., 2015, 7: 76-82.

[10] J.R. Morones, J.L. Elechiguerra, A. Camacho, et 
al., The bactericidal effect of silver nanoparticles. Nanotechnology, 2005, 16: 2346-2353.

[11] N. Savithramma, M. Linga Rao, P. Suvarnalathadevi. Evaluation of antibacterial efficacy of biologically synthesized silver nanoparticles using stem barks of Boswellia ovalifoliolata Bal. and Henry and Shorea tumbuggaia Roxb. Journal of Biological Sciences, 2011, 11: 39-45.

[12] N. Savithramma, M. Lingarao, S.K.M. Basha. Antifungal efficacy of silver nanoparticles synthesized from the medicinal plants. Der Pharma Chemica, 2011, 3: 364372 .

[13] G. Seema, C. Amrish. Bio synthesis and anthelmintic activity of silver nanoparticles using aqueous extract of Saraca indica leaves. International Journal of Therapeutic Applications, 2012, 7: 9-12.

[14] C. Sundaravadivelan, P.M. Nalini, P. Sivaprasanth, L. Kishmu. Biosynthesized silver nanoparticles from Pedilanthu stithymaloides leaf extract with antidevelopmental activity against larval instars of Aedes aegypti L. (Diptera, Culicidae). Parasitol. Res., 2013, 112: 303-311.

[15] M. Kumara Swamy, K.M. Sudipta, K. Jayanta, S. Balasubramanya. The green synthesis, characterization, and evaluation of the biological activities of silver nanoparticles synthesized from Leptadenia reticulata leaf extract. Appl. Nanosci., 2014, 5: 73-81.

[16] K. Vasanth, K. Ilango, R. Mohan Kumar, et al., Anticancer activity of Moringa oleifera mediated silver nanoparticles on human cervical carcinoma cells by apoptosis induction. Colloids. Surf. B., 2014, 1: 354-359.

[17] H.M.E. Rafie, M.A.A. Hamed. Antioxidant and anti-inflammatory activities of silver nanoparticles biosynthesized from aqueous leaves extracts of four Terminalia species. Adv. Nat. Sci: Nanosci. Nanotechnol, 2014, 5: 1-11.

[18] R. Bhuvaneswari, N. Chidambaranathan, K. Jegatheesan. Hepatoprotective effect of Embilica officinalis and its silver nanoparticles against ccl4 induced hepatotoxicity in wistar albino rats. Digest Journal of Nanomaterials and Biostructures, 2014, 9: 223-235.

[19] G. Seema, C. Amrish, M. Avijit, M. Rupa. Green synthesis of silver nanoparticles using Arnebia nobilis root extract and wound healing potential of its hydrogel. Asian. J. Pharm., 2014, 8: 95-101.

[20] V. Yakolev, Y.O. Golubeva. Synthesis optimisation of Lysozyme Monolayer-Coated silver nanoparticles in aqueous solution. J. Nanomater, 2014, 2014: 1-8.

[21] G.B. Neus, F. Merkoci, J. Piella, V. Puntes. Synthesis of Highly Monodisperse Citrate-Stabilized Silver Nanoparticles of up to $200 \mathrm{~nm}$ : Kinetic Control and Catalytic Properties. Chem. Mater., 2014, 26: 2836-2846.

[22] R. Zamiri, B.Z. Azmi, H.A. Ahangar, et al., Preparation and characterization of silver nanoparticles in natural polymers using laser ablation. Bull. Mater. Sci., 2012, 35: 727-731.

[23] J. Harra, J. Makitalo, R. Siikanen, et al., Size-controlled aerosol synthesis of silver nanoparticles for plasmonic materials. J. Nanopart. Res., 2012, 14: 1-10.

[24] S. Iravani, H. Korbekandi, S.V. Mirmohammadi, B. Zolfaghari. Synthesis of silver nanoparticles: chemical, physical and biological methods. Res. Pharm. Sci., 2014, 9: 385-406.

[25] K. Vithiya, R. Kumar, S. Sen. Bacillus sp. mediated extracellular synthesis of silver nanoparticles. Int. J. Pharm. Pharm. Sci., 2014, 6: 525-527.

[26] M. Anamika, C. Sanjukta, M.R. Prashant, W. Geeta. Evidence based green synthesis of nanoparticles. $A d v$. Mater. Lett., 2012, 3: 519-525.

[27] K.N. Reddy, C.S. Reddy. First Red List of medicinal plants of Andhra Pradesh, India-Conservation assessment and management planning. Ethnobotanical Leaflets, 2008, 12: $103-107$

[28] N. Savithramma, P. Yugandhar, R. HariBabu, K. Siva Prasad. Validation of Indigenous Knowledge of Yanadi Tribe and Local Villagers of Veyilingalakona- A Sacred Grove of Andhra Pradesh, India. J. Pharm. Sci. Res., 2014, 6: 382-388.

[29] N. Savithramma, P. Yugandhar, M. Lingarao. Ethnobotanical Studies on Japali Hanuman Theertham- A Sacred Grove of Tirumala hills, Andhra Pradesh, India, $J$. Pharm. Sci. Res., 2014, 6: 83-88.

[30] S. Karuppusamy, G. Muthuraja, K.M. Rajasekaran. Lesser Known Ethnomedicinal Plants of Alagar Hills, Madurai District of Tamil Nadu, India, Ethnobotanical Leaflets, 2009, 13: 1426-1433.

[31] A. Sudhakar, C. Ramesh, N. Nagaraju, et al., Pharmacognostical Studies on Stem \& Fruit of Syzygium alternifolium (Wight) Walp- An Endemic to South Eastern Ghats, India. Asian J. Biochem. Pharm. Res., 2012, 1: 127-138.

[32] V.V.S.S. AppalaRaju, M. Ramesh, M. Lakshmi Narsau, M. Muralikrishna Kumar. Antimicrobial Activity of the Plant Syzygium alternifolium. Asian. J. Chem., 2007, 19: 49234924.

[33] A. Rama Mohan, K.V.S.R.G. Prasad, J.A.R.P. Sharma, Hypoglycemic and antihyperglycemic activity of Syzygium alternifolium (Wt.) Walp. leaf extracts in normal and diabetic rats. Int. J. Drug Dev. Res., 2010, 2: 27-32.

[34] R.K. Sreelatha Devi, P. Sreenivasulu, S.K.M. Basha. Antioxidant activity and total polyphenols content of certain high valued medicinal plants of tirumala hills, Andhra Pradesh. Indian J. Plant Sci., 2013, 2: 93-98.

[35] B. Komuraiah, C. Srinivas, A. Niranjana Kumar, et al., Isolation of Phytochemicals From Anticancer Active Extracts of Syzygium alternifolium Walp. Leaf. Phcog. J., 2014, 6: 83-85.

[36] R. Cruickshank. Medical microbiology: a guide to diagnosis and control of infection. Livingston publishers, Edinburghand London, 1986.

[37] R.M. Gengana, K. Ananda, A. Phulukdaree, et al., A549 lung cell line activity of biosynthesized silver nanoparticles using Albizia adianthifolia leaf. Colloids and Surfaces B: Biointerfaces, 2013, 105: 87-91.

[38] G. Sharma, A.R. Sharma, M. Kurian, et al., Green synthesis of silver nanoparticle using Myristica fragrans (nutmeg) seed extract and its biological activity. Digest Journal of Nanomaterials and Biostructures, 2014, 9: 325-332.

[39] N. Jain, A. Bhargava, S. Majumdar, et al., Extracellular biosynthesis and characterization of silver nanoparticles using Aspergillus flavus NJP08: A mechanism perspective. Nanoscale, 2011, 3: 635- 641.

[40] P. Yugandhar, N. Savithramma, Biosynthesis, characterization and antimicrobial studies of green synthesized silver nanoparticles from fruit extract of Syzygium alternifolium (Wt.) Walp. an endemic, endangered medicinal tree taxon. Appl Nanosci, 2015, 
DOI: 10.1007/s13204-015-0428-4.

[41] M.M.H. Khalil, E.H. Ismail, K.Z.E. Baghdady, et al., Green synthesis of silver nanoparticles using olive leaf extract and its antibacterial activity. Arabian J. Chem., 2014, 7: 1131-1139.

[42] E.K. Elumalai, T.N.V.K.V. Prasad, V. Kambala, et al., Green synthesis of silver nanoparticle using Euphorbia hirta L and their antifungal activities. Arch. Appl. Sci. Res., 2010, 2: 76-81.

[43] I. Sondi, B.S. Sondi, Silver nanoparticles as antimicrobial agent: a case study on E. coli as a model for Gramnegative bacteria. J. Colloid. Interface. Sci., 2004, 275: 177-182.
[44] C. Krishnaraj, R. Ramachandran, K. Mohan, et al., Optimization for rapid synthesis of silver nanoparticles and its effect on phytopathogenic fungi. Spectrochim Acta, Part A, 2012, 93: 95-99.

[45] C. Baker, A. Pradhan, L. Pakstis, et al., Synthesis and antibacterial properties of silver nanoparticles. J. Nanosci. Nanotechnol, 2005, 5: 24-29.

Copyright $\subset 2015$ Pulicherla Yugandhar and Nataru Savithramma. This is an open-access article distributed under the terms of the Creative Commons Attribution License, which permits unrestricted use, distribution, and reproduction in any medium, provided the original author and source are credited. 